\title{
Application of a bottom-up approach to reduce healthcare disparity between the urban and rural areas
}

\section{Agnieszka Malicka}

University College London, United Kingdom

(iD) https://orcid.org/0000-0002-0933-5590

Corresponding author: agnieszka.malicka76@gmail.com

\section{Namrita George}

Sri Ramachandra Medical College and

Research Institute, Chennai, India

(iD -

DOI: https://doi.org/10.20883/medical.e568
Keywords: Barriers to Healthcare, Rural Healthcare, Antenatal Care, Child Malnutrition, Bottom-up approach, ASHWINI.

Published: 2021-11-26

How to Cite: Malicka A, George N. Application of a bottom-up approach to reduce healthcare disparity between the urban and rural areas. Journal of Medical Science. 2021:90(4):e568. doi:10.20883/medical.e568.

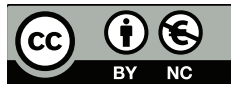

(C) 2021 by the author(s). This is an open access article distributed under the terms and conditions of the Creative Commons Attribution (CC BY-NC) licencse. Published by Poznan University of Medical Sciences

\begin{abstract}
Disparity in access to healthcare between rural and urban regions occurs world-wide, both in higher and lower income countries. To offset poor health outcomes a number of approaches to structuring healthcare services can be used. Several factors have been identified to play a role, however there are differing degrees of severity in how they contribute to the healthcare gap - depending on whether a higher or lower income country is being evaluated. Traditionally, healthcare systems worldwide adopt a top-down approach which is initiated by large institutions providing resources required for large scale projects along with centralisation of efforts. Although it does lead to change, the results can be short-lived. The authors discuss the bottomup approach used in ASHWINI organisation in Gudalur, India which allowed for the development of accessible and sustainable healthcare system managed by the community. Other projects, based in part on the principles of a bottom-up approach, have been applied in other countries to reduce healthcare disparities. When designed to deliver geographically-accessible, locally managed, culturally appropriate care, the bottom-up approach can provide sustainable results and being universal in nature, it could be applied in other setting with similar set up.
\end{abstract}

\section{Introduction}

A world-wide disparity is observed in access to healthcare between the rural and urban regions. Literature suggests that the rural areas tend to have poorer health outcomes compared to their urban counterparts, with physical, cultural and resource-related factors which affect the inequal- ity in the provision of healthcare. The disparity is observed in countries with high and low Gross National Income (GNI) per capita alike, although a greater difference is visible in the states with a lower GNI per capita.

Improving access to healthcare in the rural areas is challenging and several factors have been identified to play a role, where resource availabil- 
ity constituting one of the main ones. However, a simple redistribution of the resources does not resolve the issue, as certain there are other barriers hindering the improvement including rural patients' reluctance to seek help, distance from the services, absence of transport to access services, insufficient number of healthcare professionals, as well as financial constraints [1-3].

\section{Global disparity}

The paper on the rural health infrastructure in United States has evaluated the efforts to improve the disparity; however, as previously highlighted, much remains to be done, particularly in terms of the smallest and very remote areas which have been mostly affected [3]. A study in Ghana highlighted illiteracy and language barrier as factors which limit rural healthcare provision in their environment [4]. Furthermore, in India, large disparities were the underlying cause of the change, and in 2016 and 2018 the main emphasis was focused on strengthening the primary healthcare system as well as on improving the access to the secondary and tertiary services by introducing nearly universal health insurance scheme [5]. Nevertheless, despite the problem recognition and the efforts taken, health disparity still remains a global concern. As mentioned in the previous section, a number of factors contribute to the aforementioned disparity, although they vary in degree - depending on whether a higher or lower income country is evaluated. In a number of cases, the rural areas experience a shortage of qualified staff, as the personnel might be unwilling to live and work in a more remote area with fewer amenities. In order to circumvent this problem, incentives should be offered which would attract and retain staff in the rural environment. The type of the incentive, however, will vary depending on the country's socio-economic development, with enforced legal contracts and mandatory rural bonded scholarships playing a more crucial role in countries, such as Australia and Japan, whereas in Cambodia and Laos financial incentives are more frequent [6].

\section{Approaches to reduce disparity in healthcare} Traditionally, healthcare systems worldwide adopt a top-down approach which is initiated by large institutions providing resources required for large scale projects, along with the centralisation of efforts. Although it does lead to a change, the results can be only temporary. In fact, a top-down approach can result in little engagement and lack of ownership on the front line. Furthermore, since it does not address the underlying behaviour of a community, it often tends to leave the project unsustainable in the long term. A different approach is a bottom-up initiative which aims to achieve a change on a local level by involving the community, as it empowers the people to drive the project which gives more sustainable results [7].

To discuss the issue of healthcare access and to review the success of any approach to offset poor health outcomes, the authors of this paper use an example of a bottom-up initiative implemented in rural India. We provide a review of an institution established in a lower-middle income country, as a case study in order to draw parallels with other systems implemented world-wide, as well as to derive universally applicable conclusions.

\section{Bottom-up approach in Gudalur Valley}

Gudalur is a municipality situated in Tamil Nadu state in South India. According to the latest classification of the World Bank, India belongs to the lower-middle GNI per capita group [8]. It is the second most populated country in the world (with the estimated population of 1.4 billion), experiencing both rapid economic growth and significant overpopulation [9]. Technically, India's healthcare system is free to all citizens and the public sector, i.e. Government Hospitals offer free healthcare at the point of use. Unfortunately, due to staff and equipment shortages reported in the government-run healthcare, many people turn to the private sector. Nevertheless, efforts are underway to reduce these disparities by implementing programmes, such as universal sanitation coverage, the provision of clean cooking fuel, as well as vaccinations for children under age of 2 and many others [10]. Nonetheless, the limited resources constitute a contributing factor to the many health problems faced by the population. To address health disparities in the rural areas, the 2018 centralised budget strategy 'Ayushman Bharat' was focused on strengthening the primary healthcare system and on the introduction 
of a nearly universal health insurance to improve the secondary and tertiary care access [5]. Despite the efforts of the government to improve India's healthcare in recent decades, less than $5 \%$ of gross domestic product has been dedicated to health expenditures [10].

The Gudalur Valley is home to more than 20,000 Adivasis (tribal people) who until recently had no access to healthcare, as they have been unable to easily access government-ran health services. Therefore, a charitable organization referred to as ASHWINI, The Association for Health Welfare in the Nilgiris, was established to improve the service provision and to decrease Adivasis' mortality rate. The association was founded in 1990, and its aim has always been to achieve 'an accessible, effective and sustainable health system that is owned by the community' [11]. The project started with the focus to address infectious diseases, malnutrition and both maternal and infant mortality among the vulnerable Adivasi population living in Nilgiri mountains in South India. The approach adopted by the founders focused on employing locals as staff, as well as on encouraging the community's participation in the decision-making process in order for the tribal team to take over the management. This sustainable and people-focused initiative grew and evolved into a hospital which caters to over 20000 Adivasis, with 8 accessible community based centres. The constant development has led to the opening of a nursing school, thus allowing the tribal people to enrol in studies, train in dentistry and involve in other courses, such as administration and physiotherapy. Furthermore, ASHWINI encourages international links, and their medical elective programme has been beneficial for both visitors and hosts, increasing the Adivasis' connection to the world [11]. The relationship between selected aspects of healthcare and the bottom-up approach employed in the ASHWINI model is discussed in the sections below.

\section{Malnutrition}

Malnutrition in India continues to be a recognised problem. In 1975 the Government of India introduced Integrated Child Development Services (ICDS) - a programme aiming to deliver healthcare, nutrition benefits, health follow-ups, immunisations and other services for children up to six years old, as well as for pregnant and breastfeed- ing women. These basic healthcare needs were to be provided by health centres, situated all over India. However, in 2015-2016 The National Family Health Survey in India highlighted that 1 in 2 children still suffered from nutritional deficiencies. In fact, one of the ICDS's pitfalls, particularly in terms of tribal communities, was the geographical inaccessibility of health centres [12].

Although less than $50 \%$ of the population were of normal weight, only a small proportion sought help, presumably partly due to the geographical inaccessibility, as mentioned above. The alarming figures have been the reason behind ASHWINI's outreach programme which has been training community health workers who visit tribal hamlets, assess growth of children under the age of 5 and identify patients who need nutrition benefits. In spite of the fact that $45 \%$ of the local population suffers moderate to severe malnutrition, between 2017-2018, 92.3\% of all children had their growth monitored, and 595 children benefited from the ICDS programme [13].

\section{Antenatal care, maternal and infant mortality among the Adivasis}

Taking into consideration the fact that, according to data collected from a few villages, infant mortality rate in the area was as high as 250 per 1000 in 1988, and several instances of maternal death were recorded, ASHWINI's initial focus was to address maternal health, antenatal and postnatal care. Both high maternal (145 deaths per 100000 live births) and high infant mortality rates (39.55 deaths per 1000 live births) constitute India's national problem [9]. Similarly to the case of malnutrition, the figures tend to be greater among the tribal communities, due to physical barriers in accessing healthcare, unsanitary conditions and poor nutritional, and hence, physiological reserve. ASHWINI owes its success to the outreach programme where health volunteers identify pregnant women in the community and monitor their progress until the delivery. In years 2017-2018, 296 tribal deliveries occurred with $91.5 \%$ of women having $>3$ antenatal follow-ups, and only 1 maternal death was noted. Nevertheless, although infant mortality rate decreased, it still remains at $21.2 \%$. In contrast to the out-of-hospital midwife-led deliveries encouraged in the West, a strong shift towards inpatient deliveries was observed in ASHWINI. In 
the period of $2017-2018,94.9 \%$ of deliveries took place in hospital, ensuring access to the sanitary conditions as well as to trained staff and necessary equipment in case of complications [13].

\section{Mental Health and use of substances}

Due to poverty and challenging living conditions, many Adivasis suffer mental health problems. ASHWINI established Mental Health Programme which between 2017-2018 identified 62 new patients suffering from mental illnesses and provided 259 patients with the treatment for their mental health condition [13].

Additionally, despite a limited access to alcohol, alcohol abuse was noted, mainly among men. Many Adivasis were also seen consuming betel nut, which has been linked to cancer. Healthcare staff have been trying to discourage the consumption of either of the substances, since they affect health negatively. This, however, comprises a difficult endeavour, due to the fact that both alcohol and betel nut are employed as a coping mechanism which helps to deal with the hardship, hunger and poverty.

\section{Comparing ASHWINI to other healthcare models used worldwide}

Discussing India's approach to healthcare deserves a separate analysis due to the population size, cultural and religious diversity. Notwithstanding the existence of a national public healthcare system, there is some diversity in the implementation and execution of health-related policies between the states, and even within the states themselves. Therefore, the analysis of the approach which aims to improve healthcare in the rural areas requires taking into account the political system of the country. India on the whole is a democratic country, i.e. its political system is generally similar to that in Northern America and the European countries [14]. This distinction renders India unique among other lower-middle income countries, which largely have a degree of authoritarian regimes, thus making the comparative process more difficult. Furthermore, a comprehensive comparison of India's healthcare system with healthcare in other lower-middle income countries would exceed the scope of one article; hence, India remains the main focus of this paper.

Up to date, the implementation of a bottom-up approach to healthcare has not been extensively discussed in the scientific literature, therefore, the evaluation of a successful initiative in the rural region of India seems valuable. Moreover, it may be a starting point for further assessment of the effectiveness of this approach with regards to improving healthcare sustainability, by means of utilising local manpower, local infrastructure and local resources.

Poverty, combined with insufficient infrastructure, including staff, equipment and facilities are frequently at the root of poor health outcomes. The problems highlighted, faced by Adivasis in Gudalur region, are experienced universally by the rural communities worldwide. The principles of ASHWINI including bottom-up approach, empowering local community and the focus on sustainability of the results are also universal in nature, indicating they could be successfully transferred to any other environment with a similar infrastructure. In 1993, India passed the Panchayat Raj Act which assigned the responsibility of developing health plans to the individual districts, expecting that a decentralised planning system would better reflect and address the local community needs and improve resource exploitation. Nevertheless, this approach was successful in certain districts, although it failed in others. It was noted that factors, such as a lack of external input from government officials, were interpreted as a lack of interest, contrary to the assumption, and thus resulted in little community involvement. The district where the state offered supervision and periodically requested reports coped better, and the local staff felt safe and encouraged. This demonstrates that locally managed services supervised by their superiors might achieve better results compared to a top-down or a bottom-up approach only [15].

In Uganda, a randomised experiment was performed which aimed to improve quality and quantity of service provision by encouraging the community to monitor local healthcare providers. The study found that community's involvement in monitoring service delivery was reflected in improved staff accountability, and increased staff efforts to serve the local population. This 
resulted in better service provision where the traditional top-down supervision has failed [16].

In Garissa District Hospital in Kenya a hybrid model of service delivery has been employed. National level ministry personnel pays regular visits to provide supervision and ensure care standards, whereas hospital management teams with the community leaders on the hospital board and continue to identify and solve problems which appear locally. The success of this model is reflected in the figures - inpatient admissions increased by $33 \%$, the number of self-discharging patients decreased by $90 \%$, number of deliveries increased by $50 \%$, while the new-born death rate decreased by $75 \%$ [17].

Taking a brief look at higher income countries, one of the quoted barriers to improving National Health Service (NHS) in the UK, is that the commissioner's vision of improvement is not shared by the organisations providing the services, thus they may not feel motivated to achieve better outcomes at a local level [18]. Therefore, little engagement on the front line is universally one of the main pitfalls of a top-down approach. In the Netherlands, healthcare is also regulated top-down [19], whereas in Switzerland bottom-up approach has been adopted. Switzerland has delegated the responsibility for the efficient medical care to the GPs, and it has transpired that the doctors participating in the scheme have shown a lot of initiative for providing quality, cost-effective service [19]. In contrast, in Scotland and Ireland, quality improvement efforts are supported by organisations which employ a hybrid model where selected components of both top-down and bottom-up approaches are implemented [20]. The abovementioned examples demonstrate that the approach to organising healthcare services varies between countries. However, it is claimed that certain features of a top-down approach, such as central coordination and pooled resources, once combined with a bottom-up ownership and engagement, can result in a successfully implemented change [7].

\section{Conclusions}

A bottom-up approach applied by ASHWINI has improved health outcomes in the area by introducing child and antenatal care, offsetting malnu- trition and addressing mental illness. ASHWINI's approach is based on universal principles, therefore, if applied in other rural areas with a similar demographic, resource and infrastructural environment, it may lead to improved healthcare outcomes.

Employing a bottom-up approach, preferably alongside the selected components of a top-down system, is essential if healthcare outcomes are to improve and the change is to be long-lived.

\section{Acknowledgements}

The authors thank Dr Shyla and Dr Nandakumar from Gudalur, ASHWINI for their support, assistance and proofreading the article.

\section{Conflict of interest statement}

The authors declare no conflict of interest.

\section{Funding sources}

There are no sources of funding to declare.

\section{References}

1. Douthit N, Kiv S, Dwolatzky T, Biswas S. Exposing some important barriers to health care access in the rural USA. Public Health. 2015 Jun;129(6):611-20. doi: 10.1016/j.puhe.2015.04.001. Epub 2015 May 27. PMID: 26025176.

2. Debate: Rural Health Care [Internet]. Royal College of Nursing. 2019 [cited 2 July 2021]. Available from: https://www.rcn.org.uk/congress/congressevents/12-rural-health-care.

3. Weisgrau S. Issues in rural health: access, hospitals, and reform. Health Care Financ Rev. 1995 Fall;17(1):114. PMID: 10153465; PMCID: PMC4193574.

4. Peprah P, Abalo E, Agyemang-Duah W, Budu H, Appiah-Brempong $E$, Morgan $A$ et al. Lessening barriers to healthcare in rural Ghana: providers and users' perspectives on the role of mHealth technology. A qualitative exploration. BMC Medical Informatics and Decision Making [Internet]. 2020 [cited 3 July 2021];20(1). Available from: https://bmcmedinformdecismak.biomedcentral.com/articles/10.1186/ s12911-020-1040-4.

5. Mohan $P$, Kumar R. Strengthening primary care in rural India: Lessons from Indian and global evidence and experience. Journal of Family Medicine and Primary Care [Internet]. 2019 [cited 5 July 2021];8(7). Available from: https://www.ncbi.nlm.nih.gov/pmc/ articles/PMC6691438.

6. Zhu A, Tang S, Thu N, Supheap L, Liu X. Analysis of strategies to attract and retain rural health workers in Cambodia, China, and Vietnam and context influencing their outcomes. Human Resources for Health [Internet]. 2019 [cited 17 October 2021];17(1). Available from: https://human-resources-health.biomedcentral.com/articles/10.1186/s12960-018-0340-6. 
7. Ogunlayi F, Britton P. Achieving a 'top-down' change agenda by driving and supporting a collaborative 'bottom-up' process: case study of a large-scale enhanced recovery programme. BMJ Open Quality [Internet]. 2017 [cited 20 June 2021];6(2). Available from: https:// www.ncbi.nlm.nih.gov/pmc/articles/PMC5699149.

8. World Bank Country and Lending Groups [Internet]. The World Bank I Working for a World Free of Poverty. [cited 22 July 2021]. Available from: https://datahelpdesk. worldbank.org/knowledgebase/articles/906519world-bank-country-and-lending-groups.

9. The World Factbook. India [Internet]. Cia.gov. [cited 16 June 2021]. Available from: https://www.cia.gov/ the-world-factbook/countries/india.

10. Gupta I, Patel N, Tikkanen R, Osborn R, Mossialos E, Djordjevic $A$ et al. International Health Care System Profiles. India [Internet]. The Commonwealth Fund. 2020 [cited 21 June 2021]. Available from: https:// www.commonwealthfund.org/international-healthpolicy-center/countries/india.

11. ASHWINI (Association for health welfare in the Nilgiris) A health program for the people by the people [Internet]. ASHWINI. [cited 21 June 2021]. Available from: http://ashwini.org/new.

12. Rajpal S, Joe W, Subramanyam M, Sankar R, Sharma $S$, Kumar A et al. Utilization of Integrated Child Development Services in India: Programmatic Insights from National Family Health Survey, 2016. International Journal of Environmental Research and Public Health [Internet]. 2020 [cited 22 June 2021];17(9). Available from: https://pubmed.ncbi.nlm.nih.gov/32375377.

13. Annual Report- April 2017-March 2018 [Internet]. ASHWINI. [cited 21 June 2021]. Available from: http:// ashwini.org/publications/Annual_report-17-18.html

14. The Economist Intelligence Unit. Democracy Index 2020 In sickness and in health? [Internet]. The Economist Intelligence Unit; 2021. Available from: https:// www.eiu.com/n/campaigns/democracy-index-2020.
15. Murthy N. Decentralized Health Planning: Lessons from Two Districts in India. Journal of Health \& Population in Developing Countries [Internet]. 1998 [cited 12 October 2021]; Available from: https://pubmed. ncbi.nlm.nih.gov/12322440.

16. Björkman M, Svensson J. Power to the People: Evidence from a Randomized Field Experiment on Community-Based Monitoring in Uganda*. Quarterly Journal of Economics [Internet]. 2009 [cited 31 October 2021];124(2):735-769. Available from: https:// www.researchgate.net/publication/51993017_Power_to_the_People_Evidence_from_a_Randomized_ Field_Experiment_on_Community-Based_Monitoring_in_Ugnada.

17. Gill Z, Bailey P. Bottom up and top down: A comprehensive approach to improve care and strengthen the health system. Journal of the Pakistan Medical Association [Internet]. 2010 [cited 13 October 2021]; Available from: https://www.researchgate. net/publication/50286434_Bottom_up_and_top_ down_A_comprehensive_approach_to_improve_ care_and_strengthen_the_health_system.

18. The Health Foundation. What's getting in the way? Barriers to improvement in the NHS [Internet]. The Health Foundation; 2015. Available from: https:// www.health.org.uk/publications/what's-getting-inthe-way-barriers-to-improvement-in-the-nhs.

19. Top down or bottom up? [Internet]. Healthcare-ineurope.com. 2007 [cited 14 October 2021]. Available from: https://healthcare-in-europe.com/en/news/ top-down-or-bottom-up.html.

20. Mcdermott A, Hamel L, Steel D, Flood P, Mkee L. Hybrid healthcare governance for improvement? Combining top-down and bottom-up approaches to public sector regulation. Public Administration [Internet]. 2015 [cited 13 October 2021];93(2):324344. Available from: https://onlinelibrary.wiley.com/ doi/abs/10.1111/padm.12118. 